\title{
Correlation between the Bone Densities Jaws and Cervical Vertebrae through Computed Tomography with Multislice CT (Hounsfiled Scale). Osteoporosis Local or Systemic
}

\author{
Watanabe PCA ${ }^{1 *}$ and Cheade MCC $^{2}$ \\ ${ }^{1}$ School of Dentistry of Ribeirão Preto and Chief of Radiology and Radioprotection Section, University of São Paulo, Brazil \\ ${ }^{2}$ School of Dentistry, Master of University of São Paulo, Brazil \\ *Corresponding author: Watanabe PCA, Full Professor at University of São Paulo, School of Dentistry of Ribeirão Preto and Chief of Radiology and \\ Radioprotection Section, Brazil, Email: watanabe@forp.usp.br
}

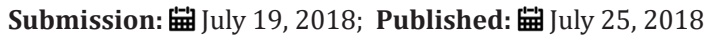

\section{Introduction}

In Brazil a Life expectancy at birth it's almost 76 years old. With the increase of the average years lived by Brazilians, can we predict that in the future, gains in this indicator will not come as easily. More intervention will be necessary in the causes of death that affect the elderly, for example the osteoporosis, as well as more investments in prevention and treatment, becoming a public health concern. Osteoporosis is the most common metabolic bone disease, affecting one in two women and one in five men aged above 50 years in the world. It is a skeletal disorder characterized by compromises bone strength that predisposes individuals to an increased risk of fractures. This change is responsible for the imbalance of the mechanics of the skeleton, increased number of fractures, notably in the spine, femoral neck and distal of the radio. This can also be seen in the maxillomandibular region, most obviously in the mandible, with decreased cortical thinning and inferior mandibular body $[1,2]$. Dual X-ray absorptiometry (DXA) and quantitative computed tomography (QCT) have been standard examination protocols in the assessment of bone mineral densities [3-5].

Rehabilitation through dental implants has been a good alternative for the population worldwide, and this technique is evident in dentistry. The bone quality and bone quantity are factors considered fundamental in the diagnostic evaluation of this rehabilitation procedure to consolidation of the boneimplant interface and that can influence surgical technique. The classification of bone quality proposed by Lekholm \& Zarb [6], which is mainly based on the subjective feeling of the surgeon during drilling. So, numerous studies report implant treatment outcome by using other approaches to assess bone tissue before and during implant treatment. To evaluate the bone mineral density of the patient through DXA or HU are methods used before and after procedures to enable correct postoperative results.
The use of Hounsfield units (HUs) from CT scanning to assess regional BMD of the column has recently been studied and the correlations between $\mathrm{HU}$ and bone mineral density have been established [7], mainly because they are directly related to tissue attenuation coefficients. The information provided by a simple HU measurement can alert the treating physician to decreased bone quality, which can be useful in both medically and surgically managing these patients with a view to implant procedures. As described by Pickhardt et al. [8], when CT scans are obtained for other clinical indications, they may also be used for "opportunistic screening for osteoporosis" [8]. The Computed tomography (CT) is currently the only diagnostically justifiable imaging technique that allows at least rough conclusion about the structure and density of the jaws bone, for assessing the relative distribution of compact and cancellous bone. Modern radiology imaging software programs allow allow the calculation of the region of interest (ROI) on CT scans without any additional cost or radiation exposure.

There was a high correlation between CT values and the bone density mineral (DEXA) and can be used in an opportunistic screening system for osteopenia/osteoporosis [5,9]. DEXA can be used in conjunction with the CT to confirm the screening diagnosis, forming a comprehensive screening tool for bone loss from CT images. In this study we propose to evaluate the correlation of the densities jaws and based cervical vertebrae of the Hounsfield scale, found in dental routine scans and correlate their values to identify possible localized or systemic osteoporosis. Our methods were based on Norton \& Gamble [10] parameters to classify patients about HU densities.

The cervical vertebrae have an average density (in units of HU) values of 222.02, 257.82 and 393.08 respectively. The mandibular 
condyles we find that on average bone density for the right condyles (RC) of all individuals in the analysis is $291.71 \mathrm{HU}$ and average bone density for left condyle (LC) is 303.49 HU. Maxilla and mandibular regions average bone density is $181.65 \mathrm{HU}$ to 46 tooth and 173.23 HU to 36 tooth, for tooth 13 is $378.10 \mathrm{HU}$ and the tooth $23,349.44$ HU.

Analysis densities (in HU) can classify subjects into two groups. The first group, individuals with local osteoporosis (two or fewer bone densities below $200 \mathrm{HU}$ ). In the second group individuals with systemic osteoporosis, 3 or more bone densities below $200 \mathrm{HU}$.

Early diagnosis of osteoporosis by bone density measurements allows proper management of osteoporosis to reduce the risk of fractures and the risk of tooth loss $[1,2,11,12]$. Bone strength reflects the integration of bone mineral density (BMD) and bone quality. Osteoporosis must be detected and treated early to avoid fragility and fractures $[1,2,13]$.

Computed tomography (CT) is considered the method of choice for study of bone structures, one of its main advantages is threedimensional information presented in a series of thin slices of the internal structure of the study, where the resulting information does not suffer by superposition anatomical structures [5,14-16]. Tay et al. [5], correlated the values of bone density by dual energy X-ray Absorptiometry (DXA) with the values of the bone densities of CT and concluded that there is a strong correlation between the values assessed by two methods and they can be used together to diagnose osteoporosis. Anderson \& Schreiber [9], evaluated 25 patients, mean age of 71.3 years, with DXA and CT of the lumbar spine and was obtained correlation of the values and concluded that there is a strong correlation between the two osteoporosis diagnostic methods, classifying the types of bone as normal, (average density 133HU), osteopenic (average 100.8 HU) and osteoporotic (average of $78.5 \mathrm{HU}$ ). Oliveira et al. [17] studied $27 \mathrm{CT}$ maxilla and mandible of patients and assessed the bone densities through two software Dental CT and E-film, regions studied and categorized as type 1 bone above $400 \mathrm{HU}$, type 2 and 3 between $400 \mathrm{HU}$ to $200 \mathrm{HU}$, type 4 above $200 \mathrm{HU}$.

The DXA is used to quantify and qualify the bone density in the hip bone, femur, forearm and also when the jaw for evaluation of localized osteoporosis, showing that the disease is systemic bone by being in various places on the bones of the body $[1,4,5,18$ 20] and CT proved as efficient as the DXA for diagnosis of bone densities in different bones in the body. Lee et al. [18] evaluated the lumbar spine 128 women who had CT and DEXA, the trabecular portion of the L4 vertebra was analyzed and values in HU and BMO were determined and compared, showing a strong correlation between the two methods for osteoporosis diagnosis. In this study, correlated the densities of the jaws with the cervical spine, although little studied, is part of the spine, and found strong correlations when there are low densities in the jaw and spine, thus suggesting a classification of systemic osteoporosis for patients.
So, we could conclude that computed tomography used in dentistry appears to be a means of diagnosing osteoporosis located in the jaw or systemic.

\section{References}

1. Adams JE (2013) Advances in bone imaging for osteoporosis. Nat Rev Endocrinol 9(1): 28-42.

2. Watanabe PCA, Watanabe MGC, Tiossi R (2012) How dentistry can help fight osteoporosis. In: Dionyssiotis Y (Ed.), Osteoporosis. Intech 40: $953-$ 51.

3. Wakimoto M, Matsumura T, Ueno T, Mizukawa N, Yanagi Y, et al. (2012) Bone quality and quantity of the anterior maxillary trabecular bone in dental implants sites. Clin Oral Implants Res 11: 1314-1319.

4. Weishaupt D, Schweitzer ME, Di Cuccio MN, Whitley PE (2001) Relationships of cervical, thoracic, and lumbar bone mineral density by quantitative CT. J Comput Assist Tomogr 25(1): 146-150.

5. Tay WL, Chui CK, Ong SH (2012) Osteoporosis screening using real bone mineral dentistry estimation from diagnostic CT images. Acad Radiol 19(10): 1273-1282.

6. Lekholm U, Zarb GA (1985) Patient selection and preparation. In: Branemark PI, Zarb GA, Albrektsson T (Eds.), Tissue integrated prostheses: osseointegration in clinical dentistry. Quintessence, Chicago, USA, pp. 199-209.

7. Schreiber JJ, Anderson PA, Rosas HG, Buchrealholz AL, Au AG (2011) Hounsfield units for assessing bone mineral density and strength: a tool for osteoporosis management. J Bone Joint Surg Am 93(11): 1057-1063.

8. Pickhardt PJ, Pooler BD, Lauder T, del Rio AM, Bruce RJ, et al. Opportunistic screening for osteoporosis using abdominal computed tomography scans obtained for other indications. Ann Intern Med 158(8): 588-595.

9. Anderson PA, Schreiber MD (2011) CT Hounsfield units for assessing bone mineral density-A tool for osteoporosis management. Disorders of Spine and Peripheral Nerves. $27^{\text {th }}$ Annual Meeting of the AANS/CNS Arizona, USA, pp. 9-12.

10. Norton MR, Gamble C (2001) Bone classification: an objectives scale of bone density using that computerized tomography scan. Clin Oral Implants Res 12(1): 79-84.

11. White SC (2002) Oral radiographic predictors of osteoporosis. Dentomaxillofac Radiol 31(2): 84-92.

12. Santiago RC, Vitral RWF (2006) Bone mineral density assessment methods and denstistry application. Pesq Bras Odontopediatr Clin Integr 6(3): 289-94.

13. Cann CE, Genant HK, Ettinger B, Gordan GS (1980) Spinal mineral loss in ophorectomized women: determination by computed tomography. JAMA 244(18): 2056-2059.

14. Arellano JCV (2001) Computed tomography (CT) in the diagnosis and control of temporomandibular joint dysfunctions. JBA 1(4): 315-323.

15. Santos AR (2010) Bone quality of the mandible in the edentulism by computer tomographyda [dissertation]. São José dos Campos, Institute of Research and Development, University of Vale do Paraíba, Brazil.

16. Ferreira MC (2010) Review the thickness of the alveolar, buccal and lingual bone boards jaws through the cone beam computed tomography (cone beam) [dissertation]. University of São Paulo, São Paulo, Brazil.

17. Oliveira RC, Leles CR, Normanha LM, Lindh C, Ribeiro-Rotta RF (2008) Assessments of trabecular bone density at implant sites on CT images. Oral Surg Oral Med Oral Pathol Oral Radiol Endod 105(2): 231-238. 
18. Lee IJ, Lee JJ, Bae JH, Hwang E, Lee S, et al. (2013) Significance of osteoporosis in facial bone density using computed tomography. J Craniofac Surg 24(2): 428-431.

19. Pervaiz K, Cabezas A, Downes K, Santoni BG, Frankle MA (2013) Osteoporosis and shoulder osteoarthritis: incidence, risk, factors, and surgical implications. J Shoulder Elbow Surg 22(3): e1-e8.
20. Engelke K, Adams JE, Armbrecht G, Augat P, Bogado CE, et al. (2008) Clinical use of quantitative computed tomography and peripheral quantitative computed tomography in the management of osteoporosis in adults: the 2007 ISCD official positions. J Clin Densitom 11(1): 123162.
Creative Commons Attribution 4.0 International License

For possible submissions Click Here

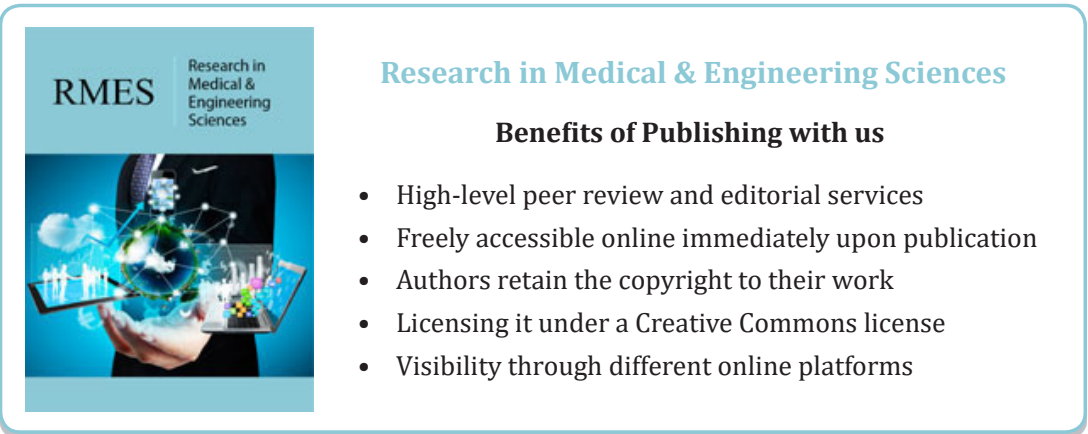

